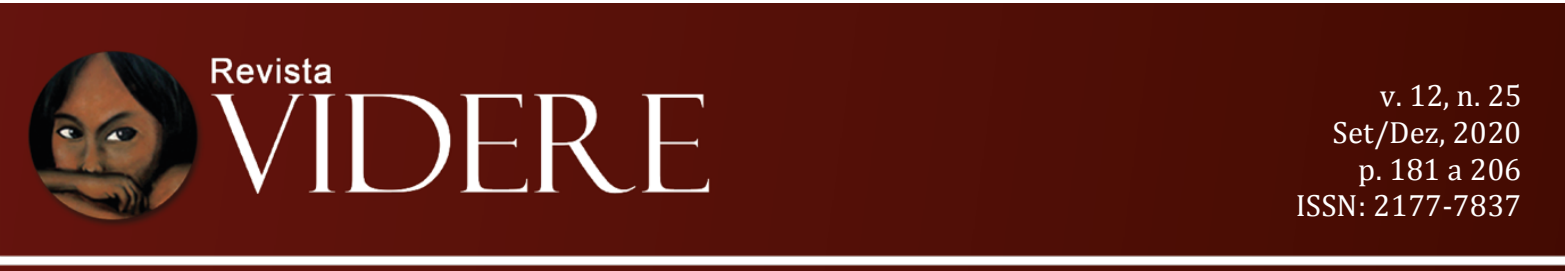

\title{
POR UMA ECONOMIA POLÍTICA DA PENA DESDE O SUL: REFLEXÕES ACERCA DO CONTROLE PENAL NOS PAÍSES DE CAPITALISMO DEPENDENTE NA PÓS GRANDE INDÚSTRIA
}

\author{
FOR A POLITICAL ECONOMY OF PUNISHMENT FROM THE SOUTH: \\ REFLECTIONS ON PENAL CONTROL IN CONTRIES OF DEPENDENT CAPITALISM \\ IN THE POST BIG INDUSTRY
}

POR UNA ECONOMÍA POLÍTICA DE LA PENA DESDE EL SUR: REFLEXIONES SOBRE CONTROL PENAL EN LOS PAÍSES DEPENDIENTES DEL CAPITALISMO EN LA POST-GRAN INDUSTRIA

\author{
Carla Benitez Martins \\ Doutorada em Sociologia \\ Professora no curso de Direito da UFJ \\ carla.benitez.martins@gmail.com \\ OrcidID: https://orcid.org/0000-0002-1365-560X
}

\begin{abstract}
Resumo: Reivindicando a necessidade de realização de uma leitura histórico-estrutural do sistema penal e incorporando as heranças dos estudos de economia política da pena desenvolvidos durante o século XX, este trabalho busca contribuir na atualização das reflexões na área diante da atual etapa do padrão de acumulação da ordem do capital. Partiremos de uma defesa da atualidade da teoria do valor de Karl Marx, especialmente em reflexões presentes na obra Grundrisse quanto às particularidades da subsunção do trabalho ao capital em cada momento acumulativo, apontando elementos para o que se configuraria como etapa do "intelecto geral". Esta defesa nos permitirá configurar uma específica compreensão da etapa da Grande Indústria, a divergir nos detalhes daquelas concepções pósfordistas que superam a categoria "classe trabalhadora" e a centralidade do conflito capitaltrabalho. Desde estes aportes teóricos, o trabalho buscará alinhar tal concepção geral às particularidades do controle penal nesta etapa, divergindo, em partes, da leitura eurocentrada da ultrapassagem da disciplina da carência e o alcance do governo do excesso (positivo ou negativo) por meio do desenvolvimento de novas tecnologias do poder na etapa da "sociedade do controle", com a presença de um sistema penal de tipo atuarial. De outro lado, ainda que distante de uma contraposição a tais fundamentais elaborações, reivindicaremos a tradição da compreensão do desenvolvimento desigual e combinado do capitalismo para demonstrar como se configura o sistema penal na realidade do capitalismo periférico e dependente na fase da Pós Grande Indústria e sua relação com suas características constitutivas de ser sistema de extermínio.
\end{abstract}

Palavras-chave: Economia política da pena. pós grande indústria. capitalismo dependente. 


\title{
POR UMA ECONOMIA POLÍTICA DA PENA DESDE O SUL: REFLEXÕES ACERCA DO CONTROLE PENAL NOS PAÍSES DE CAPITALISMO DEPENDENTE

\begin{abstract}
Proposing a historical-structural reading of the penal system and incorporating the legacies of the political economy of punishment studies developed during the XX century, this paper intends to contribute in the updating of these reflections based on the current stage of the capitalist accumulation. It will start from a defense of the topicality of the Karl Marx's theory of value, tooking especially the formulations of their Grundrisse about the particularities of the subsumption of labor to capital in each capitalist accumulation stage, indicating elements for diagnosis of the contemporary, called "general intellect". This defense will allow us to configure a specific understanding of this stage of the Big Industry, diverging in the details of those post-Fordist conceptions that surpass the category "working class" and the centrality of the capital-labor conflict. From these theoretical contributions, the work will seek to align this general and abstract conceptions about criminal control to the particularities of criminal control at this stage, all to diverge, in several forms, from the eurocentric readings of the overcoming of the discipline of need and the achievement of governance of excess (positive or negative) through the development of new power in the "control society" stage, with the presence of an actuarial type of criminal system. On the other hand, although far from a counterposition to such fundamental elaborations, we will claim the tradition of the univen and combined development of capitalism to demonstrate how the penal system is configured in dependent and peripherical countries in the phase of the Post Big Industry, and their relation with the constitutive characteristis of an extermination system.
\end{abstract}

Keywords: Political economy of punishment. post big industry. Capitalism dependent.

Resumen: Reivindicando la necesidad de realizar una lectura histórico-estructural del sistema penal e incorporando las herencias de los estudios de economía política de la pena desarrollados durante el siglo XX, este trabajo busca contribuir a la actualización de las reflexiones en el área ante la etapa actual del patrón de castigo. acumulación del orden de capital. Partiremos de una defensa de la actualidad de la teoría del valor de Karl Marx, especialmente en las reflexiones presentes en la obra Grundrisse en cuanto a las particularidades de la subsunción del trabajo al capital en cada momento acumulativo, señalando elementos para lo que se configuraría como una etapa del "intelecto general". Esta defensa nos permitirá configurar una comprensión específica del escenario de la Gran Industria, para divergir en los detalles de aquellas concepciones posfordistas que superan la categoría "clase trabajadora" y la centralidad del conflicto capital-trabajo. A partir de estos aportes teóricos, el trabajo buscará alinear esta concepción general con las particularidades del control criminal en esta etapa, divergiendo, en parte, de la lectura eurocéntrica de la superación de la disciplina de la necesidad y el alcance del gobierno del exceso (positivo o negativo) a través del desarrollo. de nuevas tecnologías de poder en la etapa de "sociedad de control", con presencia de un sistema penal de tipo actuarial. Por otro lado, aunque lejos de oponernos a elaboraciones tan fundamentales, reivindicaremos la tradición de entender el desarrollo desigual y combinado del capitalismo para demostrar cómo el sistema penal se configura en la realidad del capitalismo periférico y dependiente en la fase post-Gran Industria y su relación con sus características constitutivas de ser un sistema de exterminio.

Palabras clave: Economía política de la pena. posT gran industria. capitalismo dependiente 


\section{POR UMA ECONOMIA POLÍTICA DA PENA DESDE O SUL: REFLEXÕES \\ ACERCA DO CONTROLE PENAL NOS PAÍSES DE CAPITALISMO DEPENDENTE \\ NA PÓS GRANDE INDÚSTRIA}

\section{Introdução}

Podemos dizer que o século XX inaugura uma nova racionalidade no padrão de acumulação do capital. Neste trabalho buscaremos apreender as mudanças qualitativas nas relações sociais na ordem do capital, em diálogo com autores que, de diferentes maneiras, procuram evidenciar as transformações estruturais dos "anos dourados" da primeira metade do século XX para os tempos instáveis que se instauram na década de setenta, tratando de identificar as transformações na natureza do trabalho e nas dinâmicas de produção e a concomitância de novas configurações de subjetividades na etapa de acumulação capitalista que alguns irão denominar de Pós-fordismo, Pós-modernidade, Modernidade recente, Império e que nós defendemos, na esteira de importantes teóricos como Eleutério Prado (2005), como Pós-Grande Indústria, na sua relação com o neoliberalismo.

Nosso objetivo é, diante deste arcabouço, analisar o papel do controle penal neste período de nova racionalidade mundial. Isto tem gerado muitas controvérsias entre os pensadores críticos, não no sentido da percepção do diagnóstico, mas sim nas explicações estruturais do fenômeno.

Em uma fase histórica de incontestáveis mudanças profundas nas formas de produção de mercadorias, de metamorfoses no mundo do trabalho, de conexões e intercâmbios internacionais de outra qualidade e natureza, de alterações abruptas nas formas de sentir e amar, este trabalho estará fora de moda, pois não se renderá às narrativas fragmentadas e, muito longe de ignorar essas reais transformações, pautar-se-á pela "antiquada" disposição de compreender os fenômenos criminológicos contemporâneos desde uma leitura da totalidade social.

Beberemos, inicial e brevemente, em fonte longínqua, nos primeiros escritos a pautar a conhecida "economia política da pena", compartilhando a preocupação de "checar a veracidade empírica da hipótese de uma relação entre variáveis estruturais fundamentais, especialmente as de natureza socioeconômicas e a evolução das instituições penais" (MELOSSI, 2006, p. 10).

São "estudos que descrevem o papel exercido pelos sistemas punitivos na afirmação histórica das relações de produção capitalista" (DE GIORGI, 2006, p. 34) e o primeiro deles, muito antes da consolidação da criminologia crítica no campo intelectual (que se deu apenas na década de 70), foi o de George Rusche e Otto Kirchheimer, com sua primeira versão em 1933, que se propõe a analisar o surgimento da pena de prisão como pena por excelência e a consolidação do capitalismo, a fim de perceber a relação codeterminada entre ambas. Este 


\section{POR UMA ECONOMIA POLÍTICA DA PENA DESDE O SUL: REFLEXÕES ACERCA DO CONTROLE PENAL NOS PAÍSES DE CAPITALISMO DEPENDENTE}

estudo, acompanhado de Evgeni Pachukanis e depois Michel Foucault tiveram importante função na inauguração do debate sobre a violência estrutural e a função não declarada da pena de prisão, imbuída de objetivos políticos, peça importante no controle social do capital.

Ocorre que, com a passagem para o período de maior domínio tecnológico, financeirização da economia e flexibilização e precarização das relações de trabalho, alguns estudiosos afirmarão que a relação entre essas principais instituições de controle social com a "fábrica" está, de algum modo, perdida ou se teria tornado obsoleta.

Para De Giorgi (2006, p. 56), a análise não deve ser pautada na relação entre desemprego e encarceramento, mas sim entre economia e dispositivos de controle, pois "as suas análises (refere-se ao debate mais usual da economia política da pena) não levam em conta os processos de transformação do trabalho, limitando-se à observação do tratamento penal do desemprego, do não-trabalho".

Tal leitura se aproxima, com especificidades, do que pretendemos definir aqui como leitura histórico-estrutural do sistema penal no capitalismo, uma continuidade atualizada e aperfeiçoada dos intentos de George Rusche e Otto Kirchheimer. Longe de uma leitura mecânica e engessada, mas ciente das tendências e continuidades de etapas de acumulação do capital e comportamentos do controle sócio penal.

Se, originalmente, com a fixação das casas de trabalho no período mercantilista, núcleo impulsor da consolidação das prisões tempos depois, foi baseada no princípio do less eligibility, que define que a condição material da parcela mais pauperizada da classe trabalhadora servirá como limite externo para qualquer modulação das condições do regime penal, atualmente, muito se discute de sua permanência, em modelo muito mais complexo, pois, para além da mecânica relação entre desemprego-encarceramento, "na definição das fronteiras nas quais a less eligibility opera, outros fatores sociais intervém para delinear a condição do proletariado e a sua relação com o regime penal” (DE GIORGI, 2006, p. 57).

Como adiante abordaremos em detalhe, estas mudanças estruturais dos padrões de acumulação da ordem do capital vem gerando diferenças teóricas de compreensão de seus significados e do quanto isso se traduz em diferentes configurações do controle social do capital e, dentro disso, do controle penal.

De nossa parte, indagamos qual seria a verdadeira extensão da superação da lógica disciplinar e definição de uma "sociedade do controle" e o que isso diz sobre a adequação ou não de uma leitura a partir da "economia política da pena" no tempo presente.

Até onde podemos dizer que nos deslocamos de uma tendência "autoritárioressocializante" a uma "detentivo-neutralizante"? Mais do que isso, enquanto pesquisadora 


\section{POR UMA ECONOMIA POLÍTICA DA PENA DESDE O SUL: REFLEXÕES ACERCA DO CONTROLE PENAL NOS PAÍSES DE CAPITALISMO DEPENDENTE}

que se detém na observação dos fenômenos desde a realidade do capitalismo dependente brasileiro, até onde esta classificação das etapas de controle social pode ser generalizável?

Parece-nos que na pós-grande indústria - como defenderemos adiante -, não há substituição, mas sim acumulação com o padrão de produção da grande indústria, o mesmo ocorrendo com o controle sócio penal, que nem historica nem atualmente cumpriu e cumpre papéis idênticos nas realidades do capitalismo central e do capitalismo periférico.

\section{Pressupostos teóricos para nossa leitura da economia política da punição contemporânea}

O diálogo respeitoso que travaremos em seguida com algumas leituras mais conceituadas na atualidade no campo criminológico crítico partirá de uma definição - não oposta, porém diferenciada destas - acerca do impacto das mudanças do padrão acumulativo do capital e o papel do controle penal no controle social do capital contemporâneo.

Pensamos ser necessário estabelecer um olhar teórico de longa duração sobre os padrões estruturais do controle penal, pois, a título de exemplo, em um período histórico no qual o hiperencarceramento se apresenta como um fenômeno mundial, independentemente de um aumento real dos índices de criminalidade e, além disso, gerido por governos desde os de extrema direita aos ditos progressistas ${ }^{1}$, há, de fato, algo de tendencial e estrutural neste processo que, em nossa opinião, não se explica apenas em uma relação de causa-efeito entre economia e sistema penal, mas também na compreensão dos limites absolutos alcançados pela ordem sociometabólica do capital.

O que isso significaria? Partimos da percepção de que o capital é um modo sociometabólico de controle social específico e histórico. O capital se sobrepôs aos demais modos de produção por sua capacidade de produzir o excedente, devido a mecanismos cada vez mais aperfeiçoados de submissão e exploração do trabalho. Assim, essa "relação-capital", fundada na alienação do trabalho e extração de mais-valia, a fim de se consolidar, engloba todas as instâncias de reprodução social, de maneira dominadora, em seu círculo autoexpansivo.

O sistema do capital consolida seu controle social por meio do desenvolvimento das “mediações de segunda ordem”, que buscam naturalizar as relações e instituições, bem como

\footnotetext{
${ }^{1}$ De Giorgi (2006, p. 96) comenta a tendência de aumento do encarceramento em países europeus: "Nos últimos dez anos as taxas de aprisionamento aumentaram em cerca de $40 \%$ na Itália, Inglaterra e França, $140 \%$ em Portugal, 200\% na Espanha e nos Países Baixos. Os únicos países onde foi registrada uma ligeira contratendência foram a Alemanha, a Áustria e a Finlândia".
} 


\section{POR UMA ECONOMIA POLÍTICA DA PENA DESDE O SUL: REFLEXÕES ACERCA DO CONTROLE PENAL NOS PAÍSES DE CAPITALISMO DEPENDENTE}

torná-las a-históricas, mas que, na verdade, são formas de mediações alienadas que se impõem nas relações dos homens entre si e deles com a natureza, "da família às estruturas de controle do processo de trabalho, e variadas instituições de troca discriminadora até o quadro político de dominação de tipos muito diferentes de sociedade" (MÉSZÁROS, 2002, p. 207).

Tais mediações, articuladas estruturalmente, controlam a reprodução geral do capital. Isso significa que, no capitalismo, o controle social precisa ser retirado do corpo social e que, portanto, trata-se de se constatar que as mediações são inerentes às relações sociais de maneira universalizante, mas o subtrair-se alienante é característico da relação-capital.

Entendemos que o Estado não está subordinado aos imperativos econômicos, mas são interdependentes. O Estado capitalista, em suas diferentes modalidades, atua também como mediador, garantindo o funcionamento dessa ordem sociometabólica como um todo. Portanto, o Estado atua de diversas maneiras, seja com formas de consenso, seja com paliativos que disfarcem disparidades, seja como braço direito das instabilidades econômicofinanceiras do sistema, seja como o agente repressor por excelência. Por isso que se deve ter cautela ao qualificá-lo como superestrutura, pois se trata de uma das bases sustentadoras desse sociometabolismo.

Como buscaremos abordar em seguida, a etapa da Pós Grande Indústria coincide com o que István Meszáros denomina como ativação dos limites absolutos do capital, sendo tais mediações de segunda ordem incapazes de deslocar as contradições inerentes ao sistema com a mesma eficiência, instalando-se um continuum de crise - uma crise estrutural do capital (Meszárós) ou crise civilizacional (Lowy) ou, como prefere Marildo Menegat (2012), um estado de barbárie permanente. Neste estágio, o controle penal adquire maior centralidade, aspecto que buscaremos desvendar a seguir, com sua heterogeneidade em termos geopolíticos.

\section{Breve histórico do surgimento da economia política da punição}

A construção de nossos argumentos parte de um pressuposto constituído pelos precursores das teorizações acerca da economia política da punição.

Como sabemos e adiante especificaremos, no capitalismo as relações políticas e econômicas se alteram profundamente e as pessoas trabalhadoras são subtraídas de seus meios de produção e sua liberdade encontra-se permitida desde que submetida à venda da sua força de trabalho. Isso altera sobremaneira os mecanismos de controle da população, pois "com a afirmação do modo de produção capitalista, a condição do proletariado se torna uma função 


\title{
POR UMA ECONOMIA POLÍTICA DA PENA DESDE O SUL: REFLEXÕES ACERCA DO CONTROLE PENAL NOS PAÍSES DE CAPITALISMO DEPENDENTE
}

principalmente econômica: a condição material do proletariado é determinada diretamente no interior dos processos de organização e de divisão do trabalho" (DE GIORGI, 2006, p. 40).

Sendo assim, Dario Melossi e Massimo Pavarini afirmam que o equivalente na sociedade feudal era outro, o que nos explica porque a prisão não era a pena por excelência naquele período:

\begin{abstract}
Por conseguinte, na presença de um sistema socioeconômico como o feudal, no qual ainda não se historicizara completamente a ideia do 'trabalho humano medido no tempo' (leia-se trabalho assalariado), a pena-retribuição, como troca medida pelo valor, não estava em condições de encontrar na privação do tempo o equivalente do delito. O equivalente do dano produzido pelo delito se realizava, ao contrário, na privação daqueles bens socialmente considerados como valores: a vida, a integridade física, o dinheiro, a perda de status (MELOSSI, PAVARINI, 2006, p. 22).
\end{abstract}

Georg Rusche, acompanhando Pachukanis, possuem a fundamental preocupação de descrever a reciprocidade dos processos de penalização e a consolidação do mercado de trabalho no capitalismo. Eles comparam, a partir da universalização do princípio da troca de equivalentes, o contrato como fixação do tempo de trabalho e a sentença como fixação do tempo de reclusão.

Pachukanis, jusfilósofo russo de fundamental importância teórica e militante nos anos da Revolução Russa, insere o sistema penal em sua análise mais ampla do fenômeno jurídico centrada no desenvolvimento dialético das categorias jurídicas e econômicas, sendo a relação econômica a contraface da relação jurídica, entendida como a relação entre sujeitos de direito que realizam a troca de mercadorias por meio de um contrato.

Assim, Pachukanis (1988, p.118) estuda o fenômeno jurídico não através da norma, mas sim da relação jurídica e, para ele, "o direito privado reflete o mais diretamente possível as condições gerais de existência da forma jurídica como tal, o Direito Penal por sua vez representa a esfera onde a relação jurídica atinge o mais alto grau de tensão". Com a mercantilização mundial e a expansão do capital para todas as esferas do ser social, as formas de punição passam a ser medidas pelo tempo.

Assim, o que Pachukanis desenvolve nesse período é a noção de equivalência da pena de prisão em relação ao crime no capitalismo, porém, para além disso, George Rusche e os que virão posteriormente buscam explicar, especialmente desde a realidade europeia, a função política da prisão como controle do trabalho excedente e de adestramento e docilização das e dos trabalhadores para os novos mecanismos de exploração. 


\section{POR UMA ECONOMIA POLÍTICA DA PENA DESDE O SUL: REFLEXÕES ACERCA DO CONTROLE PENAL NOS PAÍSES DE CAPITALISMO DEPENDENTE

transformar o criminoso não-proprietário no proletário não-perigoso, um sujeito de necessidades reais adaptado à disciplina do trabalho assalariado (SANTOS, 2006, p. 8).

Desde estes aportes teóricos, Georg Rusche desenvolve a ideia do princípio da less elegibility (ou seja, o princípio da menor preferibilidade), elemento fundador da lógica da pena de prisão na fundação do capitalismo, que significa assumir condições sempre mais danosas à pessoa presa do que ao trabalhador(a) que esteja fora das grades. Portanto, "numa economia capitalista, isso significa que será a condição do proletariado marginal que determinará o rumo da política criminal e, por conseguinte, o regime de 'sofrimento legal' imposto àqueles que forem punidos por desrespeito às leis" (DE GIORGI, 2006, p. 38).

Dario Melossi e Massimo Pavarini (2006, p. 38) contribuem nessa análise a partir da descrição do que seria os primórdios antecedentes da fixação da pena de prisão como pena por excelência, fundada no princípio da less elegibility, qual seja a criação das casas de trabalho. Eles realizam um panorama europeu do surgimento das casas de trabalho, suas especificidades em cada país, de acordo com suas peculiaridades econômicas e também culturais e religiosas e constatam que, na essência, "o trabalho forçado nas houses of correction ou workhouses era direcionado, portanto, para dobrar a resistência da força de trabalho e fazê-la aceitar as condições que permitissem o máximo grau de extração de maisvalia".

De um lado, é fundamental a afirmação de Georg Rusche de que "os fundamentos do sistema carcerário encontram-se no mercantilismo; sua promoção e elaboração foram tarefas do Iluminismo" (RUSCHE; KIRCHHEIMER, 2004, p. 109). Com o passar do tempo e do desenvolvimento do novo modo de produção, o tempo medido progressivamente deixa de se tornar produtivo nas prisões, mas, mesmo assim, continua fazendo sentido nesta ordem social a equivalência crime-prisão, pois "baste a experiência do tempo escandido, do tempo medido, a forma ideológica vazia, que nunca é apenas ideia, mas que morde na carne e na cabeça do indivíduo que se deve reformar, estruturando-o com parâmetros utilizáveis pelo processo de exploração" (MELOSSI; PAVARINI, 2006, p. 91).

Esta é a base dos raciocínios em torno da economia política da punição. Daqui em diante, buscaremos nos posicionar acerca dos debates sobre as mutações do capitalismo contemporâneo e as novas características do controle penal global, bem como de suas particularidades na realidade dependente/periférica.

\section{Debates sobre a atualização da economia política da punição}




\section{POR UMA ECONOMIA POLÍTICA DA PENA DESDE O SUL: REFLEXÕES ACERCA DO CONTROLE PENAL NOS PAÍSES DE CAPITALISMO DEPENDENTE}

Neste artigo, dialogaremos mais precisamente com a perspectiva que relaciona a superação do período do fordismo (a fase transicional denominada por esses autores como pós-fordismo) com a passagem de uma sociedade disciplinar a uma sociedade de controle. Neste grupo incluímos aqui, especialmente, Alessandro De Giorgi, interlocutor de Antonio Negri no campo da sociologia da violência.

Costuma-se dividir, ainda que com variáveis terminologias, a história dos processos de produção no capitalismo em manufatura (de meados do XVI ao último quartel do XVIII), grande indústria competitiva, grande indústria monopolista e pós-grande indústria (década de 70), sendo neste último a transição do sistema de máquinas para a fase do "intelecto geral”, da produção de conhecimento científico e de alta tecnologia.

Para Eleutério Prado, um elemento fundamental para a compreensão de tais etapas é a distinção de subsunção formal e subsunção material do trabalho ao capital.

O processo de trabalho acontece dentro de um processo de produção. No capitalismo, o processo de produção significa, necessariamente, a venda da força de trabalho do trabalhador. Assim, podemos afirmar que qualquer processo de trabalho exige algum nível de presença e autenticidade do trabalhador, pois, como afirma Eleutério Prado, "é inerente a determinação subjetiva posta pelo trabalhador, já que o objeto moldado por sua atividade precisa ter existido antes em sua imaginação, de um modo ideal” (PRADO, 2005, p. 121).

O que ocorre é que, na primeira etapa de desenvolvimento do capitalismo, ainda que o trabalhador fosse expropriado dos meios de produção e tivesse, necessariamente, que se submeter à relação-capital, o processo de produção, diante da mais precária existência de capital permanente, ainda dependia mais do processo criativo do trabalhador. O mais-valor era extraído da mercadoria trabalho quase que exclusivamente pelo tempo de trabalho, a conhecida extração de mais-valor absoluta:

Daí que, de um ponto de vista lógico, a subsunção formal seja compatível apenas com a extração da mais-valia absoluta, ou seja, do mais trabalho que é arrancado do trabalhador pelo prolongamento da jornada de trabalho. A extração da mais-valia relativa só pode vir a ocorrer quando o capital passa a revolucionar não apenas as relações entre os diversos trabalhadores, mas também a natureza do trabalho e os modos de trabalhar, por meio da transformação do processo produtivo pela aplicação consciente da ciência e da tecnologia (PRADO, 2005, p. 122).

E, sendo assim, a extração de mais-valia relativa se hegemoniza nessa segunda etapa, da grande indústria, quando as máquinas se aperfeiçoam e integram os processos de produção 


\section{POR UMA ECONOMIA POLÍTICA DA PENA DESDE O SUL: REFLEXÕES ACERCA DO CONTROLE PENAL NOS PAÍSES DE CAPITALISMO DEPENDENTE}

e o trabalho se torna mais compartimentalizado, automático, castrador de criatividade e autenticidade da e do trabalhador(a):

De um ponto de vista histórico, a subsunção formal do trabalho ao capital está associada ao período da cooperação manufatureira, quando então predomina a extração de mais-valia absoluta. Nessas condições de produção, a possibilidade de obtenção de mais-valia relativa é limitada. Somente com o advento da grande indústria, quando a subsunção real do trabalho ao capital torna-se efetiva e se generaliza, é que passa a predominar o modo relativo de extração de mais-valia em relação ao absoluto, o qual, aliás, nunca desaparece. Quando o capital passa a controlar o modo de trabalhar, consegue obter aumentos da produtividade do trabalho que reduzem o custo de reprodução da força de trabalho, diminuindo consequentemente a necessidade de capital variável para gerar um determinado montante de valor adicionado, o que se traduz, ao final, em aumento da mais-valia (PRADO, 2005, p. 123).

Como colocado acima, esta fase se aperfeiçoa da etapa concorrencial para a monopolista. Diante da dinamicidade inerente da ordem sociometabólica do capital, precisase expandir e acumular cada vez mais e a possibilidade de geração de superlucros só se aperfeiçoa com a tendência monopolista. Conforme analisa o autor abaixo:

Entretanto, como ressalta Mandel, a busca para manter as taxas de lucro acima da média de modo durável por parte dos capitais mais poderosos apenas se torna uma norma quando o capitalismo concorrencial é substituído pelo capitalismo monopolista. Eis que o monopólio seja ele de terra, da reserva de força de trabalho ou da tecnologia é que permite a obtenção de superlucros (PRADO, 2005, p. 124).

Portanto, nesta fase de consolidação da grande indústria, com o predomínio das grandes empresas monopolistas, enraíza-se o fordismo, processo de trabalho que permite a produção em massa, com suas linhas de montagem, controle dos tempos e dos movimentos das e dos trabalhadores(as). Como dito acima, as funções são fragmentadas e ocorre uma mais profunda "separação entre elaboração e execução no processo de trabalho" (ANTUNES, 2006, p. 25).

Compreender as principais etapas dos processos de produção no capitalismo faz-se importante para que se consiga relacionar isso ao papel disciplinar das instituições de controle penal e as caracterizações de que o período dos anos dourados do capitalismo - primeira metade do século XX - é fundamentalmente marcado por uma sociedade com característica disciplinar, seja na produção de estilo fordista, seja no cárcere e nas instituições assistenciais.

Todos estes elementos são fundamentais para que se compreenda o passo seguinte das casas de trabalho e dos primeiros cárceres. Como afirma Ricardo Antunes, "não se devem 


\section{POR UMA ECONOMIA POLÍTICA DA PENA DESDE O SUL: REFLEXÕES ACERCA DO CONTROLE PENAL NOS PAÍSES DE CAPITALISMO DEPENDENTE}

entender apenas novas técnicas de organização da produção, mas procedimentos que moldam e controlam os trabalhadores" (PRADO, 2005, p. 123) e aí acrescentamos, dentro e fora da indústria. A grande indústria necessita de uma rede de instituições e mediações sociais capazes de sustentar essa submissão da e do trabalhador(a), dentre elas o sistema penal:

Na sociedade de produção de mercadorias, a reprodução ampliada do capital pela expropriação de mais-valia da força de trabalho - a energia produtiva capaz de produzir valor superior ao seu valor de troca (salário), como ensina Marx -, pressupõe o controle da classe trabalhadora: na fábrica, instituição fundamental da estrutura social, a coação das necessidades econômicas submete a força de trabalho à autoridade do capitalista; fora da fábrica, os trabalhadores marginalizados do mercado de trabalho e do processo de consumo - a chamada superpopulação relativa, sem utilidade na reprodução do capital, mas necessária para manter os salários em níveis adequados para valorização do capital -, são controlados pelo cárcere, que realiza o papel de instituição auxiliar da fábrica. Assim, a disciplina como política de coerção para produzir sujeitos dóceis e úteis, na formulação de Foucault, descobre suas determinações materiais na relação capital-trabalho assalariado, porque existe como adestramento da força de trabalho para reproduzir o capital (MELOSSI; PAVARINI, 2006, p. 6).

O século XX demonstrou a capacidade de extensão da racionalidade do capital, incrementando sua capacidade produtiva à custa de um desperdício institucionalizado crescente. Ou seja, para que se alcançasse um crescimento constante era necessário ampliar o consumo mundial, por meio de um "consumo de massa" e de uma cada vez maior queda da taxa de utilização, bem como o incremento do valor excedente, por meio de uma intensificação da exploração de um mínimo trabalho necessário.

Essa nova racionalidade inicia-se após a crise de 1929/33 e se aperfeiçoa após a Grande Guerra, com uma série de medidas políticas, econômicas e sociais que possibilitam o deslocamento das barreiras do capital, como as estratégias keynesianas, a fixação de um Sistema Monetário Internacional, a criação de instituições mediadoras internacionais, tais como Banco Mundial, FMI e ONU, as nacionalizações de empresas privadas falidas, adaptação do Estado ao "boom" das empresas transnacionais, perpetuação da dependência do "Terceiro Mundo", o aperfeiçoamento do complexo industrial-militar, desenvolvido à custa de uma utilização nefasta da ciência e da tecnologia.

Massimo Pavarini, desde a realidade europeia, analisará como, nos ditos acima anos dourados do capitalismo, período de enraizamento do processo de produção fordista e experimentações de Estados de Bem-Estar Social em países ditos "centrais", a relação entre cárcere e políticas de assistência dialeticamente cumpria essa função de apoio à garantia do 


\section{POR UMA ECONOMIA POLÍTICA DA PENA DESDE O SUL: REFLEXÕES \\ ACERCA DO CONTROLE PENAL NOS PAÍSES DE CAPITALISMO DEPENDENTE}

processo de subsunção real do trabalho, ou seja, de controle das contradições deste processo de alienação do trabalho no capitalismo.

Esse foi um momento de transformações marcantes no controle social e, da mesma forma, no controle penal, concretizando o que ele denomina como "gestão tecnocrática da sociedade". Pavarini descreve que, nesse período, a fim de reduzir o conflito social e permitir uma organização racional do trabalho, ocorrem transformações nos mecanismos e instituições de controle social, vivenciando-se o que ele denomina como capilaridade do controle, tornando-se mais difuso.

Portanto, as políticas assistenciais, ao mesmo tempo em que garantiam - por um período - uma maior harmonia social, também objetivavam, no seu âmago, introduzir cada vez mais os trabalhadores no mercado consumidor e, portanto, era parte de uma saída liberal para maior expansão e acumulação centralizadora do capital. Mas, essa harmonização é relativa e o deslocamento das contradições temporário.

Nesse período de ascensão do Estado Social, fortalece-se um processo de desinstitucionalização. Isso, muitas vezes, aparece unicamente como triunfo de uma hipótese reabilitadora, sem se relacionar com as mudanças sociais que possibilitavam e impulsionavam tal processo. A tendência dessa política desinstitucionalizadora, com a crise fiscal do Estado, é enfraquecer os aspectos assistenciais e, dentro disso, fortalecer sua frente policial.

Diante desta inflexão, abaixo tentaremos mesclar elementos gerais das transformações da década de 70 em diante no padrão de acumulação do capital com as leituras e críticas de inauguração da "sociedade do controle", aparada por um sistema penal gerencial, neutralizador e de gestão do risco. Assim, a nós nos interessa compreender a codeterminação das transformações estruturais do padrão acumulativo e o neoliberalismo para poder tratar do papel do controle penal neste período.

Considerando perigosa a definição de um marco preciso de término e início desses ciclos de acumulação do capital, apontamos aqui alguns elementos e acontecimentos que nos parecem fundamentais para a compreensão desse processo. Seriam alguns deles: a crise fiscal dos Estados intervencionistas, acompanhada de um desnível dos conflitos entre as classes sociais desfavorável ao capital, fruto do fortalecimento sindical e dos movimentos sociais nos anos anteriores; a crise do petróleo de 1974, com a subida abrupta de seus preços; e a ruptura por parte do governo estadunidense com o Acordo de Bretton Woods, ou seja, com o fim do ouro como lastro e a ampla impregnação de dólares mundialmente, gerando o aumento abrupto dos juros e a preferência dos capitalistas pelo investimento financeiro ao invés do 


\section{POR UMA ECONOMIA POLÍTICA DA PENA DESDE O SUL: REFLEXÕES ACERCA DO CONTROLE PENAL NOS PAÍSES DE CAPITALISMO DEPENDENTE}

âmbito produtivo. Tudo isso soa como um grito pela desregulamentação financeira e acumulação flexível.

Enquanto as estratégias keynesianas se desfaziam nos países da Europa ocidental, bem como nos Estados Unidos, na América Latina da década de 80 seus países estavam ávidos por empréstimos e, a cada oscilação do dólar, não conseguiam honrar seus compromissos financeiros. Do desrespeito do Presidente Nixon ao acordado na Conferência de Bretton Woods e a consequente multiplicação dos juros da dívida já grande, que se torna astronômica, contraída por esses países, é que se explica o elemento político de que, na década de 80 , os países periféricos não suportam a recessão e a crise da dívida e a eles é imposto um programa disciplinar fiscal pelo FMI.

Exige-se, assim, uma política fiscal muito mais rigorosa, com a cobrança de juros altíssimos, o que faz com que os países periféricos entrem em uma corrida pelo aumento do superávit primário para que sua dívida não seja desvalorizada e, assim, os juros não aumentem. É um ciclo sem fim que condena tais países que a ele se submetem.

Este processo de financerização e mundialização do capital não significa um deslocamento da centralidade do trabalho no capitalismo, pois continua sendo a sua venda a única fonte, por excelência, de valorização do valor. A tendência é a fusão cada vez mais forte entre os grandes grupos financeiros e as transnacionais (com caráter produtivo/industrial), o primeiro pressionando a maior e "melhor" exploração de seus e suas trabalhadores e trabalhadoras.

Esta atual etapa de transformações políticas e econômicas tem reflexos marcantes no processo de produção e nas características da subsunção do trabalho ao capital. Trata-se de um período transicional, da análise de uma tendência de transformações a se aprofundarem, o que não supera em absoluto o período anterior.

Eleutério Prado contribui nessa análise ao não negar a teoria do valor de Marx, mas sim atualizá-la, o que denomina como sua (des)medida do valor. Costura seu raciocínio a partir de uma passagem dos Grundrisse, onde Marx explica que, com o maior desenvolvimento da grande indústria, a criação de riqueza dependerá menos do tempo de trabalho utilizado e mais do quanto de ciência e tecnologia são postos no processo de trabalho mesmo:

Dito de outro modo, o valor transformado em preço de produção já não é mais apenas um quantum de tempo de trabalho, mas se torna influenciado, de modo qualitativo, pelos conhecimentos científicos e tecnológicos mobilizados no processo de produção com o concurso necessário dos trabalhadores, durante o tempo de trabalho (PRADO, 2005, p. 125). 


\section{POR UMA ECONOMIA POLÍTICA DA PENA DESDE O SUL: REFLEXÕES ACERCA DO CONTROLE PENAL NOS PAÍSES DE CAPITALISMO DEPENDENTE}

Ainda de acordo com este trecho da obra marxiana, nessa fase o trabalhador tenderia a ocupar um lugar diferenciado no processo de produção, não mais inserido nele, mas o gerenciando. Isso significa que estaríamos em uma terceira etapa do processo de subsunção do trabalho ao capital, não mais estando alheio ao processo como um todo, funcionando como mero reprodutor de movimentos de parte do processo de produção, como hegemonicamente se dava no período da grande indústria, mas sim detendo conhecimento fundamental para a própria realização da mercadoria produzida e, por isso, em um retorno ao processo singular e criativo, ainda que suas energias continuem profundamente subsumidas à relação-capital, portanto, um trabalho sofisticadamente alienado.

Assim, se ele deixa de estar intercalado, mesmo se é liberto materialmente do processo de produção, o sistema de produção, no qual se encontram objetivados conhecimentos científicos e tecnológicos extremamente avançados, passa a exigir dele um comprometimento subjetivo, de atenção permanente, um envolvimento intelectual com seu adequado funcionamento. A pós-grande indústria é caracterizada, por isso, pela subsunção formal, intelectual e societária do trabalho ao capital (PRADO, 2005, p. 125-126).

Estas mudanças em curso aprofundam uma das mais impactantes contradições, apresentada como limite absoluto da ordem sociometabólica do capital, qual seja a necessidade cada vez maior de menos trabalho vivo e o surgimento de um desemprego em nível crônico e incorrigível.

Por fim, os conhecimentos científico e tecnológico tornam-se centrais do processo de acumulação de capital nesta etapa e, para que este sistema possa continuar se reproduzindo, acumulando e expandindo, é preciso que se controle, que se privatize, que se mercantilize todo esse conhecimento potencialmente coletivo e de domínio público. Os direitos de propriedade intelectual, a renda tecnológica e os sistemas de patentes são, assim, imprescindíveis para essa domesticação e este fenômeno também é traço fundamental da financerização:

Sem que as formas anteriores, relativa e absoluta, deixem de existir, a maisvalia extraordinária, sob a forma de renda tecnológica e financeira (oriunda de direitos de reprodução, marca e propriedade intelectual), torna-se agora um meio privilegiado de obtenção de ganhos monopolistas (PRADO, 2005, p. 124).

As mudanças são profundas, dúbias e transitórias. Caberá a nós compreendê-las desde a percepção de que o essencial do capital se mantém. 


\section{POR UMA ECONOMIA POLÍTICA DA PENA DESDE O SUL: REFLEXÕES ACERCA DO CONTROLE PENAL NOS PAÍSES DE CAPITALISMO DEPENDENTE}

Quanto aos mecanismos de controle, para De Giorgi viveríamos nesta etapa de acumulação capitalista da pós-grande indústria (por ele denominada como pós-fordismo) uma sociedade do controle ou sociedade da vigilância, sendo superado o regime disciplinar a partir do esgotamento da estrutura produtiva fordista.

$\mathrm{Na}$ sociedade disciplinar superou-se a ideia de suplícios e mortes e se instaurou a ordem da recuperação, disciplinamento e docilização dos corpos, "passíveis de constituir uma massa que as nascentes tecnologias da disciplina podem forjar, plasmar, transformar em sujeitos úteis, isto é, em força de trabalho" (DE GIORGI, 2006, p. 27). Portanto, o modelo disciplinar coincidiu com o fortalecimento do Estado de Bem-Estar Social e a etapa industrial do capitalismo.

Entretanto, tal autor entende que da transição da década de setenta em diante houve o desfalecimento deste projeto disciplinar da modernidade. O processo de essencialização (ou demonização, como prefere Jock Young (2002)) necessário para a construção de inimigos opera-se por instituições que não possuem mais a disciplina como objetivo primeiro, mas sim a neutralização, seja pelas múltiplas formas de vigilância, seja pela guetização ou pelo encarceramento.

Dessa maneira, para ele, viveríamos a transição da sociedade disciplinar à sociedade de controle, sendo que a "biopolítica do poder global" garantiria mecanismos sofisticados de regulação da mão de obra útil e descartável em um espaço tornado imperial. O controle penal atual seria puramente de contenção do excedente. Para ele, "a disciplinaridade se revela cada vez mais inadequada com relação às novas formas de produção e impotente para explicitar práticas de controle eficazes no confronto com as novas subjetividades do trabalho" (DE GIORGI, 2006, p. 30).

A noção de multidão é fundamental para suas conclusões teóricas sobre o controle penal e, quanto a isso, temos ressalvas.

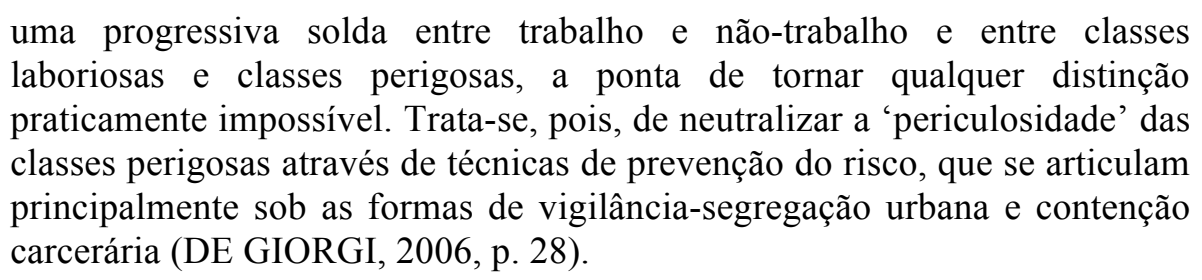

Parece-nos que a grande questão para Negri e seus seguidores, como De Giorgi, é que não se poderia falar mais em classe trabalhadora diante das transformações do processo de produção, por dois motivos. Primeiro porque tais mudanças fazem com que a linha entre trabalho e emprego seja tênue, não havendo mais o ciclo trabalho-salário-consumo-cidadania, 


\section{POR UMA ECONOMIA POLÍTICA DA PENA DESDE O SUL: REFLEXÕES ACERCA DO CONTROLE PENAL NOS PAÍSES DE CAPITALISMO DEPENDENTE}

sendo que a certos trabalhadores "não é socialmente reconhecido como condição suficiente para ter acesso a uma existência social plena" (DE GIORGI, 2006, p. 69).

Isso é perigoso, pois bem sabemos que o padrão de acumulação se altera, mas os elementos essenciais da exploração capitalista permanecem e a classe trabalhadora está mais viva (ainda que parte morta em vida, diante das precarizações de existência) do que nunca!

Segunda e problemática afirmação é a de que o domínio do capitalista não se daria mais no processo de trabalho, mas sim externamente e que seria, portanto, muito mais político do que econômico, "o domínio capitalista abandonaria o terreno do conflito contra o trabalho para deixar que ele se desenvolva entre os sujeitos do trabalho" (DE GIORGI, 2006, p. 77). Segue o autor afirmando que

são os pressupostos da produtividade do trabalho que hoje excedem a relação capitalista e não as determinações concretas desta produtividade. No nível constitutivo, ontológico, a força de trabalho contemporânea se configura como totalidade produtiva indistinta, como conjunto de potencialidades cooperativas que escapam a qualquer regulamentação: nesse sentido, ela é uma multidão (DE GIORGI, 2006, p. 78).

Para melhor compreender a delicadeza disso, vale a pena seguirmos os razoáveis apontamentos de Eleutério Prado, que, como dissemos acima, não se nega a perceber, tal como o próprio Marx já anunciava, transformações na (des)medida do valor, porém sob bases distintas e "não negacionistas" (com toda a redundância desta expressão).

À medida que se desenvolvem mais trabalhos intelectuais, mais dificuldades de medir o valor haverá, pois tais mercadorias possuem seus valores de uso medidos não apenas pelo tempo de trabalho necessário, mas também por outros referenciais qualitativos que o trabalhador carrega consigo e que se traduz no processo de produção.

O fetichismo em que caem Hardt e Negri consiste em que raciocinam sobre o caráter da produtividade do trabalho focando o resultado material do processo de produção. Como se sabe, segundo $O$ Capital a condição necessária para que o trabalho seja produtivo no capitalismo é que ele produza valores de uso que tenham mercado, mas esta não é uma condição suficiente, pois é preciso também que ele produza mais-valia para o capital. Pouca importa aqui se o valor gerado está cristalizado em produtos materiais ou imateriais ou em produtos que têm existência separada ou não do ato de trabalhar (PRADO, 2005, p. 54).

Ou seja, o predomínio dos serviços sobre os bens não seria tecnicamente o mesmo que dizer que há o predomínio de valores de uso imateriais, mas, mais do que isso, essa primeira diferenciação não impacta na essência da produção de mercadoria sob o capitalismo. 


\section{POR UMA ECONOMIA POLÍTICA DA PENA DESDE O SUL: REFLEXÕES ACERCA DO CONTROLE PENAL NOS PAÍSES DE CAPITALISMO DEPENDENTE}

Eleutério pode discordar das classificações de Negri, porém apoia a importância de se buscar "examinar as estruturas de poder cristalizadas na organização do trabalho" (PRADO, 2005, p. 56). Para ele, devemos buscar compreender as formas distintas de subordinação do trabalho ao capital ao longo da história, porém, quanto à distinção da sociedade disciplinar e da sociedade do controle, ele diz faltar a demonstração da gênese das mesmas e "por mais interessante que seja toda essa caracterização, da qual emergem duas formas sociais de estruturação do poder no capitalismo, ela permanece externa à produção" (PRADO, 2005, p. 57).

Entende o autor que Hardt e Negri estariam a sinalizar que o aspecto cooperativo do trabalho neste período histórico, diferentemente dos períodos anteriores, não é imposto e organizado de fora, sendo a cooperação intrínseca à atividade, o que pode ensejar a interpretação de que este trabalho possui autonomia em relação ao capital.

(...) concluem que a subsunção do trabalho ao capital tornou-se puramente externa ao processo de trabalho e, em consequência, arbitrária. Inferem daí que não subsiste a distinção entre capital constante e capital variável na pósgrande indústria, mesmo se os trabalhadores continuam vendendo sua força de trabalho para os capitalistas, o que, nos termos de Marx, caracteriza a subsunção formal do trabalho ao capital. Como o trabalho coletivo tornou-se para eles 'comunicativo, afetivo e imaterial' e, assim, cooperativo em si e por si mesmo, deduzem também que a produção enquanto tal tornou-se potencialmente comunista, mesmo se o modo de produção ainda continua sendo capitalista (PRADO, 2005, p. 59).

Para eles, mudanças profundas na subjetividade partem dessa dificuldade de uma nítida separação entre tempo de trabalho e de não trabalho. Negam a ideia de classe e assumem a de multidão, entendendo que "não é mais possível definir um lugar determinado de constituição da subjetividade do trabalho, de tornar extrínseca a sua produtividade e de expressão da sua conflituosidade, como era possível para a classe operária fordista" (DE GIORGI, 2006, p. 79).

Cabe-nos colocar algumas ponderações importantes acerca do caráter dúbio, contraditório e desigual dessas mudanças tendenciais, bem como reforçar a continuidade, ainda que mais sofisticada, da alienação do trabalho no capital.

Assim, pensamos que essa ponte entre as mudanças do padrão acumulativo do capital e suas estratégias de auto-expansão marcadas com a implementação disforme do receituário neoliberal em cada canto do globo e as mudanças na produção de comportamentos, formas de sentir e estar no mundo, de produção de subjetividades, faz-se 


\section{POR UMA ECONOMIA POLÍTICA DA PENA DESDE O SUL: REFLEXÕES ACERCA DO CONTROLE PENAL NOS PAÍSES DE CAPITALISMO DEPENDENTE}

imprescindível para que se alcance leituras desde a essência deste momento histórico que possam apontar cenários e possibilidades.

Assim, compreender o esfacelamento dos laços sociais, os processos de essencialização do outro, a fragmentação das lutas, o hiperconsumismo, o surgimento de novos sujeitos históricos, a intensidade e os mecanismos de controle de grupos sociais pressupõe ressignificar qualitativamente o sociometabolismo do capital. Estendemos como nossas as palavras de Ricardo Antunes sobre o impacto das mudanças entre as décadas de 70 e 80 do século passado para a classe trabalhadora:

Foram tão intensas as modificações, que se pode mesmo afirmar que a classe-que-vive-do-trabalho sofreu a mais aguda crise deste século, que atingiu não só a sua materialidade, mas teve profundas repercussões na sua subjetividade e, no íntimo inter-relacionamento destes níveis, afetou a sua forma de ser (ANTUNES, 2006, p. 23).

As especificidades da subsunção do trabalho ao capital nesse período exigem um compromisso integral da e do trabalhador(a), um "vestir a camisa" da empresa, o que causa impactos incalculáveis na sofisticação dos níveis de sua exploração e na produção de sua subjetividade.

Ricardo Antunes descreve como a incorporação do toyotismo não significou "um novo modo de organização societária, livre das mazelas do sistema produtor de mercadorias" (ANTUNES, 2006, p.40) e muito menos significaria algum tipo de progresso em relação ao fordismo, sendo o estranhamento do trabalhador no processo de produção ainda mais intensificado, ainda que complexamente mais manipulatório.

Portanto, mudanças inegáveis estão em curso, que precisam ser compreendidas nas suas profundezas, porém a lógica de reprodução do capital se mantém intacta e a classe trabalhadora continua classe trabalhadora, com toda a exploração, a desumanização e, ao mesmo tempo, uma ontológica força revolucionária, aprimorada com o alto desenvolvimento das forças produtivas.

(...) aparência da eliminação efetiva do fosso existente entre elaboração e execução no processo de trabalho. Aparência porque a concepção efetiva dos produtos, a decisão do que e de como produzir não pertence aos trabalhadores. O resultado do processo de trabalho corporificado no produto permanece alheio e estranho ao produtor, preservando, sob todos os aspectos, o fetichismo da mercadoria (ANTUNES, 2006, p. 46).

Para concluir esta etapa do raciocínio destacamos, ademais, que a alta tecnologização da produção, permeada pela aparente lógica colaborativa e cooperativa da e do trabalhador(a) vem, necessariamente, acompanhada de uma acumulação flexível, que demanda 


\section{POR UMA ECONOMIA POLÍTICA DA PENA DESDE O SUL: REFLEXÕES ACERCA DO CONTROLE PENAL NOS PAÍSES DE CAPITALISMO DEPENDENTE}

terceirizações e flexibilizações das relações laborais, bem como intensifica os processos de desenvolvimento desigual entre setores de produção e entre regiões geográficas.

Portanto, há concomitâncias de processos, na velha dicotomia do arcaico e do moderno, que sustenta ainda mais as possibilidades de expansão do capital nesta era.

É nesse contexto de transformações que De Giorgi (2006, p. 89) busca responder "quais tecnologias de controles e formas de racionalidade do domínio se constituem a partir do esgotamento do fordismo, do encerramento do ciclo industrial do capitalismo e da transformação da força de trabalho pós-fordista em multidão".

Apesar de, desde a nossa concepção, não ter havido o esgotamento do fordismo, muito menos o encerramento do ciclo industrial do capitalismo, estamos dialogando e ponderando com esse autor por entender que possui importantes contribuições, ainda que com bases teóricas distintas, o que interfere em certas análises e conclusões.

A reflexão sobre as "novas tecnologias de poder" passa pela noção de que neste período, pelas mudanças das dinâmicas das relações sociais, especialmente com as alterações no processo de trabalho, os mecanismos de controle não são individualizados, mas operam por grupos denominados "de risco", não são a partir do conflito, mas sim em uma afirmação de periculosidade e em um exercício de antecipação do provável crime a ser cometido por determinado indivíduo, componente de um determinado grupo social. Ou seja, um processo de essencialização, no qual eles se tornam em si o risco, independentemente de sua conduta.

Como afirma De Giorgi (2006, p. 91), "esta condição de não-saber qualifica os dispositivos de controle e os orienta para uma função de supervisão, de limitação do acesso, de neutralização e de contenção do excesso".

Algumas classificações concorrem para explicar tal fenômeno. Alguns dizem que estaríamos ultrapassando o Panopticon para o Oligopticon, no qual "grupos sociais restritos exercem um poder de vigilância sobre outros grupos sociais restritos" ou ao Synopticon:

\footnotetext{
$\mathrm{Na}$ 'sociedade do espetáculo' contemporânea não seriam mais os poucos a vigiar os muitos para obrigá-los a seguir as regras, mas sim os muitos, constantemente transformados em 'público', que admirariam as façanhas dos poucos e interiorizariam valores, atitudes e modelos de comportamento, tornando-se assim indivíduos responsáveis e consumidores confiáveis (DE GIORGI, 2006, p. 93).
}

Seja como for, o que se vislumbra é um conjunto "de tecnologias de controle orientadas para o internamento, para a vigilância e para a limitação do acesso" (DE GIORGI, 2006, p. 93), com a cidade cada vez mais guetizada e controlada e os estabelecimentos penais operando desde uma lógica gerencial. 
o conceito qualificante desta racionalidade é o de risco. As novas estratégias penais se caracterizam cada vez mais como dispositivos de gestão do risco e de repressão preventiva das populações consideradas portadoras desse risco. Não se trata de aprisionar criminosos perigosos individuais, isto é, de neutralizar fatores de risco individual, mas sim de gerir, ao nível de populações inteiras, uma carga de risco que não se pode (e, de resto, não se está interessado em) reduzir. A racionalidade que estamos descrevendo não é disciplinar, e sim atuarial (DE GIORGI, 2006, p. 97).

Assim, a força de trabalho excedente começa a ser controlada menos por mecanismos assistenciais e mais por "instituições penais de gestão da pobreza", sob novas técnicas e objetivos, bem como por monitoramentos eletrônicos que estabelecimentos novas dinâmicas nas grandes cidades. Daí que, para De Giorgi (2006, p. 104) "o controle se materializa numa arquitetura que não regula o encontro, mas o impede, não governa a interação, mas cria obstáculos a ela, não disciplina as presenças, mas as torna invisíveis". Ademais, tende-se a abandonar os discursos "res" (ressocializar, reinserir, reeducar etc) e assumir declaradamente uma função neutralizadora da pena.

\section{Pensar a atualização da economia política da punição desde a realidade periférica}

De todo o posto, a realidade em países de capitalismo periférico e dependente, como o caso brasileiro, sempre foi outra e essa mudança paradigmática não se aplica. $\mathrm{O}$ que não quer dizer que não sintamos os impactos da lógica gerencial na política criminal brasileira, mas, primeiro, não vivenciamos uma sociedade disciplinar tal como nas realidades europeia e estadunidense e, segundo, tal lógica é necessariamente híbrida, combinada com técnicas da máxima modernidade ao estilo "cárcere e fábrica" e, sobretudo, pelo histórico e constitutivo autoritarismo escravagista e patriarcal que funda nossa nação fraturada e imprime um papel de extermínio ao sistema penal baseado na noção de periculosidade e prevenção de riscos voltada a grupos populacionais específicos.

A dimensão da escravidão brasileira foi incomparável ao resto do mundo, diante da imensa população, de diferentes regiões da África, trazidas compulsoriamente às nossas terras para serem escravizadas; diante da centralidade dessa exploração - que necessitou de mecanismos econômicos e extra-econômicos para ser sustentada -; bem como em decorrência do máximo prolongamento possível da relação social escravista, sendo abolida 33 anos após o fim do tráfico internacional de escravas e escravos, de maneira conservadora e excludente.

Diante disso, os desafios para controle desta população avolumada e potencialmente revoltada passaram por todo o processo ideológico de desumanização, pela tentativa de 


\section{POR UMA ECONOMIA POLÍTICA DA PENA DESDE O SUL: REFLEXÕES ACERCA DO CONTROLE PENAL NOS PAÍSES DE CAPITALISMO DEPENDENTE}

aculturação e por mecanismos de repressão penal legalmente vinculados às Ordenações portuguesas de cunho inquisitorial, mas majoritariamente garantidos no espaço privado, sendo o senhor de engenho seu principal fiscalizador.

Segundo Ana Luiza Flauzina (2006, p.46), constitui-se, no período de 1500 a 1822, a “espinha dorsal da lógica de atuação do aparelho repressivo no país", enquanto um sistema naturalizador da subjugação, "de base fundamentalmente corporal".

O momento subsequente, de Independência aparente e constituição do período imperial, foi marcado por uma maior regulação legal penal interna, com uma série de previsões criminalizantes de tipificações sem vítimas, majoritariamente atreladas a aglutinação de pessoas negras em espaços públicos ou no controle de levantes e insurreições.

Com a crise econômica e o pipocar de revoltas populares em todos os cantos do país, o Código Criminal do Império, aprovado em 16 de Dezembro de 1830, acompanhado de uma série de Decretos, inauguraram os novos métodos jurídicos para "impedir a ocupação livre dos espaços públicos pela população negra" (FLAUZINA, 2006, p.56), desde a tipificação do crime de insurreição, a vedação dos cultos religiosos de origem africana, a necessidade de documentações para o "livre" trânsito - e a previsão de castigos caso não as portassem -, até a criminalização da vadiagem e da capoeira, aperfeiçoadas com o Código seguinte, em 1890.

Dessa maneira, este período consolida o monopólio institucionalizado da violência, voltado ao controle não declarado de populações - e não de indivíduos - a fim de controlar sua potência insurgente - desenvolvida pelo fortalecimento de suas identidades coletivas - e reforçar seu lugar marginal na relação de produção que se gestava.

O momento seguinte, com o fim da escravidão, marca um aprofundamento deste papel do sistema penal brasileiro até aqui narrado. A atuação do sistema penal neste período foi imprescindível para que se administrasse a transformação do escravo em liberto sem se perder o total controle social. A única maneira de bloquear o poder insurrecional da população seria transformando ex-escravos em marginais, criminalizando-os.

Os passos seguintes dessa história, ao longo do processo de modernização conservadora se sofisticam, porém mantém sua mesma diretriz. Deste período em diante, de um lado, a igualdade formal e a narrativa de um "direito penal do ato" se consagra; de outro lado, a nossa ideia de periculosidade, a nortear as contradições do direito penal moderno, ganha cor e origem com as construções institucionais da ideia de "indivíduo suspeito", a ser traduzida como a suspeição generalizada do povo negro.

Deste brevíssimo resgate dos elementos caracterizadores da vocação para o extermínio do sistema penal brasileiro, importa-nos alcançar uma importante definição 


\section{POR UMA ECONOMIA POLÍTICA DA PENA DESDE O SUL: REFLEXÕES ACERCA DO CONTROLE PENAL NOS PAÍSES DE CAPITALISMO DEPENDENTE}

relacionada à necessidade de se incorporar um raciocínio não homogêneo e eurocêntrico sobre as características e funções reais do controle penal na realidade do capitalismo dependente. Conforme Aquile Mbembe (2017) nos ensina, o deslocamento epistemológico para a compreensão dos mecanismos de controle dos grupos populacionais que podem viver e os que devem morrer deve ser desde a máxima expressão do necropoder nas plantations da escravidão moderna nas colônias do Novo Mundo.

Assim, compartilhamos da percepção de Luciano Goés de que em nossa realidade não houve a absorção de um modelo disciplinar corporal - modelo benthamiano do panóptico -, mas sim uma adaptação, uma tradução do modelo lombrosiano, sendo "o marco da construção do primeiro ‘apartheid criminológico' marginal” (GOÉS, 2016, p.198)². E o autor justifica:

Isto porque aqui não houve o disciplinamento de mão de obra para as fábricas. A disciplina na periferia sempre decorreu da necessidade da manutenção da ordem racial estabelecida, alcançada por meio da extrema violência física e mortes, instrumentos indispensáveis na dominação que afligia o corpo negro, objeto de propriedade da raça branca e de atuação da domesticação direta, ou indireta pelo medo que deveria inculcar aos demais.

Paralelamente ao Estado Social e sua política de controle social difuso, aprofunda-se o autoritarismo nos países "do lado de cá" e a existência de um sistema penal subterrâneo, não declarado oficialmente como estratégia de controle social. Isso se destacou especialmente nos anos de ditadura empresarial-militar nesses países, seja por meio de legislações contravencionais ou de ordem pública altamente seletivas, seja com as enormes cifras de detidos à espera de sentença ou pela existência de mecanismo de controle policial e prisional não-oficiais, porém amplamente executados.

Dentre as questões mais urgentes a serem reinventadas por trabalhos criminológicos críticos latino-americanos e, mais especificamente brasileiros, está a reflexão da insuficiência das fórmulas do welfarismo penal e suas consequências, pois, ainda que tenhamos uma base estrutural comum, as mutações dos padrões de acumulação do capital manifestam-se desigual e combinadamente em todo o globo.

Em desacordo parcial com o conteúdo do conceito de Estado Centauro de Loic Wacquant (2012), para nós não há possibilidade de falar do neoliberalismo apenas como uma dança das cadeiras dos gestores burgueses do Estado, como uma mudança meramente

\footnotetext{
${ }^{2}$ GÓES, Luciano. A “tradução” de Lombroso na obra de Nina Rodrigues. O racismo como base estruturante da criminologia brasileira. Rio de Janeiro: Revan, 2016, p.198. 


\section{POR UMA ECONOMIA POLÍTICA DA PENA DESDE O SUL: REFLEXÕES ACERCA DO CONTROLE PENAL NOS PAÍSES DE CAPITALISMO DEPENDENTE}

política. Há que se relacionar o fenômeno neoliberal com os impactos sociais e subjetivos das metamorfoses do mundo do trabalho, necessariamente, bem como com o processo de produção, circulação e distribuição como um todo e, no mesmo sentido, com as especificidades dos controles ideológicos e físicos, diretos e indiretos.

Em continuidade ao nosso raciocínio, Marildo Menegat, com precisão cirúrgica, capta o limite do raciocínio de Wacquant ou de qualquer pensamento que não se proponha a compreender o porquê de determinadas características sociais e institucionais do capitalismo em cada fase de acumulação a partir das intrínsecas necessidades e atuais dificuldades de “valorização do valor". Só se pode compreender o comportamento do Estado desde a noção das dinâmicas do sociometabolismo do capital.

(...) explicações como 'um novo regime econômico, baseado na hipermobilidade do capital e na flexibilidade do trabalho', pouco acrescentam além do anúncio de uma suposta materialidade que explica o movimento das políticas públicas. Por que a hipermobilidade do capital e a flexibilidade do trabalho tornaram-se imposições às lutas intestinas do campo burocrático estão longe de ser respondidas. Tem-se a impressão de que um coelho foi tirado da cartola (MENEGAT, 2012, p. 215).

Eleutério Prado afirma que o acirramento das relações entre as classes, somado aos desafios da etapa monopolista da grande indústria levaram a uma atuação mais conciliatória e social do Estado, assim como reforçaram as ideias de um liberalismo social. Porém, ressalta nossa sempre presente preocupação - que o Estado de Bem-Estar Social não chegou aqui. Isso quer dizer um estado que regulamenta a concorrência, que balanceia a relação entre capitalistas e trabalhadores, que suplementa as atividades dos capitais privados. Ao invés disso, "nos países da periferia, em que faltavam as condições materiais de desenvolvimento para chegar rapidamente ao amortecimento das lutas de classes, o Estado tornou-se desenvolvimentista" (PRADO, 2005, p. 130).

Importa aqui apenas frisar que, neste período, "o liberalismo social foi a ideologia apropriada ao período da grande indústria, quando sobrevieram as crises do final do século XIX e quando o capitalismo tornou-se monopolista" (PRADO, 2005, p. 130). No período seguinte, da pós-grande indústria:

(...) a produção de tecnologias torna-se uma atividade econômica mais e mais separada da produção propriamente dita de mercadorias. Assim, uma parte importante do capital produtivo confunde-se com o capital financeiro o qual foi desregulado nas últimas três décadas do século XX - adquirindo, inclusive, a sua lógica de valorização. Como a desregulamentação financeira, após 1980 mostrou-se condição para a reestruturação da dominação do capital, na forma da pós-grande indústria, surge a percepção 


\section{POR UMA ECONOMIA POLÍTICA DA PENA DESDE O SUL: REFLEXÕES ACERCA DO CONTROLE PENAL NOS PAÍSES DE CAPITALISMO DEPENDENTE}

de que o neoliberalismo seja o domínio do capital financeiro (PRADO, 2005, p. 126).

Ao contrário do alardeado, o Estado neoliberal não é mínimo em sua intervenção, seja política ou econômica, mas sim assume o papel de um "agente econômico ativamente passivo" (PRADO, 2005, p. 133), alicerce imprescindível da perpetuação das estripulias do mercado financeiro e aparato inteligente da contenção dos efeitos catastróficos do desemprego crônico e estrutural desta etapa do desenvolvimento do capitalismo.

Neste olhar histórico sobre as fases do processo de produção, seus respectivos modelos de Estado e suas ideologias, Eleutério destaca que o liberalismo social, embasado nas noções de igualdade formal e ampliação dos direitos sociais funcionava como solda para as relações sociais daquele período, no sentido de garantir o mais "harmoniosamente" possível que a exploração da classe trabalhadora acontecesse. Com a ativação dos limites absolutos do sociometabolismo do capital, ou seja, em uma fase na qual as contradições sociais não logram ser esquivadas, a ideologia neoliberal é a própria afirmação da contradição, como se inevitável fosse.

O Estado neoliberal é o perfeito gestor das novas maneiras de dominação do trabalho na sociedade da pós-grande indústria, de um lado aprimorando a lógica social darwinista-meritocrática, de outro legitimando a violência aos "incapazes" de contribuírem na cooperação entre trabalhador-empregador para o comum desenvolvimento do capital. Em um momento como esse, quando se atingem todos estes limites estruturais (e outros aqui não descritos), a gestão neoliberal do Estado se tornou a mais adequada. Como diz Menegat (2012, p. 208), "esta nova tipologia de estado foi um verdadeiro achado para se manter o que desmorona".

\section{Conclusão}

Ao longo do artigo, expusemos as transformações nas formas e padrões de acumulação da ordem do capital, buscando perceber as mudanças concomitantes na forma de controle penal a cada etapa. Com isso, dedicamos nossos esforços em refletir criticamente sobre essas características no período da Pós-grande indústria, dialogando e divergindo com algumas leituras sobre o modo de subsunção do trabalho ao capital nesta etapa e como isso impacta na possibilidade de atualização da economia política da pena.

Concluímos este artigo afirmando que a sociedade da Pós-Grande indústria não deixou de ser uma sociedade de produção de mercadorias, em sua essência. Entretanto, o 
estranhamento da pessoa trabalhadora no processo de produção assume outras qualidades e seu estranhamento enquanto ser genérico é ainda mais evidente. Neste cenário, faz-se imprescindível pensar como hoje o confinamento - aprisionamento - dos "inúteis" para a produção serve também ideologicamente para que os inseridos no mercado aceitem o que tiver, como tiver, sendo um dos mecanismos de materialização da lógica da competição, da meritocracia e do individualismo.

Nesse mesmo sentido, ao longo do escrito pudemos perceber a insuficiência das fórmulas dualistas e rígidas de classificação em etapas de "sociedade disciplinar" e "sociedade do controle" quando nos debruçamos sobre a realidade do capitalismo dependente e periférico, em especial observando a realidade brasileira. Para demonstrar tal incompletude e até mesmo equívoco de análise, realizou-se um breve resgate das principais características do sistema penal brasileiro, demonstrando seu caráter original e estrutural de extermínio e apontando o quanto aspectos disciplinares, neutralizadores e profundamente autoritários se mesclaram em todas as etapas de seu desenvolvimento, não se adequando tal história à classificação eurocentrada.

Podemos, depois de todo este recorrido teórico, perguntar-nos qual a importância dessas diferenciações teóricas, se todos partem de uma crítica radical ao encarceramento? Trata-se de um preciosismo teórico? Da criação de objetos na academia?

Entendemos que não. Pensamos que esta é uma importante batalha teórica e política, pois precisamos construir uma crítica criminológica radical, o que significa perceber que a aparência recrudescedora penal disfarça uma crise de dominação do capital. Compreender a essência das transformações do sociometabolismo do capital nos auxilia a identificar os melhores caminhos da crítica e das respostas programáticas anti-punitivistas e desencarceradoras.

\section{Referências}

ANTUNES, Ricardo. Adeus ao trabalho?: Ensaio sobre as metamorfoses e a centralidade do mundo do trabalho. Campinas: Editora da Universidade Estadual de Campinas, 2006.

CASTRO, Lola Aniyar. Criminologia da Libertação. Rio de Janeiro: Revan, 2005.

FERNANDES, Florestan. Mudanças sociais no Brasil. São Paulo: Global, 2008. 
FLAUZINA, Ana Luiza Pinheiro. Corpo negro caído no chão: o sistema penal e o projeto genocida do Estado Brasileiro. 2006. 145 f. Dissertação (Mestrado em Direito) - Universidade de Brasília, Brasília, 2006.

HARDT, Michael; NEGRI, Antonio. Império. Tradução de Berilo Vargas. 2 ed. Rio de Janeiro: Record, 2001.

GIORGI, Alessandro De. A miséria governada através do sistema penal. Rio de Janeiro: Revan, 2006.

GÓES, Luciano. A "tradução" de Lombroso na obra de Nina Rodrigues. O racismo como base estruturante da criminologia brasileira. Rio de Janeiro: Revan, 2016.

MARX, Karl. Manuscritos econômico-filosóficos. São Paulo: Martin Claret, 2001.

MELOSSI, Dario. Discussão à guisa de prefácio. Cárcere, pós-fordismo e ciclo de produção da 'canalha'. In: GIORGI, Alessandro De. A miséria governada através do sistema penal. Rio de Janeiro: Revan/Instituto Carioca de Criminologia, 2006.

MELOSSI, Dario; PAVARINI, Massimo. Cárcere e fábrica: as origens do sistema penitenciário (século XVI-XIX). Rio de Janeiro: Revan/Instituto Carioca de Criminologia, 2006.

MENEGAT, Marildo. Estudo sobre ruínas. Rio de Janeiro: Revan/Instituto Carioca de Criminologia, 2012.

MÉSZÁROS, István. Para além do capital: rumo a uma teoria da transição. Tradução Paulo Cezar Castanheiras e Sérgio Lessa. São Paulo: Boitempo, 2002.

MOURA, Clóvis. Dialética Radical do Brasil Negro. São Paulo: Editora Anita, 1994.

PACHUKANIS, Evgeny Bronislavovich. Teoria geral do direito e marxismo. São Paulo: Acadêmica, 1988.

PAVARINI, Massimo. Control y dominación: teorías criminológicas burguesas y proyecto hegemónico. Buenos Aires: Siglo XXI Editores Argentina, 2002.

PRADO, Eleutério. Desmedida do valor: crítica da pós-grande indústria. São Paulo: Xamã, 2005.

YOUNG, Jock. A sociedade excludente: exclusão social, criminalidade e diferença na modernidade recente. Tradução de Renato Aguiar. Rio de Janeiro: Revan: ICC, 2002.

Data de recebimento: 30.04 .2020

Data de aprovação: 05.06.2020 